DOI: $10.5277 /$ epe 160413

\title{
POTENTIAL OF VARIOUS MATERIALS FOR ADSORPTION OF MICROPOLLUTANTS FROM WASTEWATER
}

\begin{abstract}
Performance of various materials such as activated carbons, carbon nanotubes, fullerene, and aluminosilicate for aquatic adsorption of micropollutants has been compared. Micropollutants (bisphenol A (BPA) and nonylphenol (NP)) were removed from artificial effluent which was spiked with standards of those chemicals. It was found that nonylphenol was more favorable adsorbed by all the sorbents than BPA. The higher adsorption capacities for BPA and NP showed single walled carbon nanotubes and activated carbon (AKPA). Slightly lower removal efficiencies of the studied micropollutants were observed for the multi-walled carbon nanotubes and activated carbon SX2. Taking into account the porous structure of the sorbents, it can be concluded that the materials containing mesopores had lower sorption capacities for BPA and NP than materials with microporous structure. Adsorption of micropollutants was much quicker for the carbon nanotubes than for the activated carbon.
\end{abstract}

\section{INTRODUCTION}

The adsorption process is a simple and economical method for the removal of various organic micropollutants such as polycyclic aromatic hydrocarbons (PAHs), endocrine disrupting chemicals (EDCs), pesticides, surfactants and many others that cause odor and taste in water. The advantage of the adsorption over other highly effective methods of removing contaminants is associated with its high versatility against a variety of refractory substances. Furthermore, this process does not generate any by-products and the spent sorbent can be regenerated and reused [1-3].

In practice, activated carbon has found the widest application in the adsorption processes, which is due to its high efficiency and ready availability [4, 5]. Increasingly, however, it has been proposed to replace it with mesoporous aluminate adsorbents or carbon nanomaterials $[6,7]$. Especially, carbon nanotubes are more universal and have many new features resulting from their nano size, which makes them better materials

${ }^{1}$ Institute of Water and Wastewater Engineering, Silesian University of Technology, ul. Konarskiego 18, 44-100 Gliwice, Poland, corresponding author G. Kamińska, e-mail: gabriela.kaminska@polsl.pl 
compared to their macro-size counterparts. Compared to conventional carbon sorbents, nanomaterials have a highly developed surface area capable of adsorption, controlled pore size and a well-developed mesoporous structure $[8,9]$.

Among many types of carbon nanomaterials, the most frequently used for the adsorption are carbon nanotubes, and fullerenes. Their adsorbing region is the outermost surface, the space between successive layers, the interior of a cylindrical nanotube as well as grooves and cavities in a tangled bundle of nanotubes $[10,11]$. Sorption capacity of carbon nanotubes depends also on their external diameter, the amount of graphene sheets and on the presence of functional groups [12]. Furthermore, unsaturated nature of the bonds in the surface functional groups makes them highly active thereby they easily undergo aggregation, and also adsorb contaminants placed deliberately in their vicinity.

Theoretically, the entire surface of carbon nanomaterials can be treated as an adsorption layer, but as a result of strong intermolecular interactions both nanotubes and fullerenes undergo spontaneous aggregation limiting their sorption capacity [13]. Thus, the actual specific surface area which can absorb micropollutants is lower than the that calculated for the sorbent [14]. Yang and Xing [15] proposed a model of the aggregation of carbon nanomaterials. In this model, spherical fullerene nanoparticles aggregate to form increasingly larger molecules, whereby some of the adsorption surfaces become blocked. This phenomenon is not observed in the case of carbon nanotubes, because their shape and length completely prevent the formation of closed voids. Taking into account many aspect of new adsorbents, an interesting question is their real performance for removal of contaminants and their comparison with conventional adsorbents.

The main objective of this study was to analyze the structural composition of carbon nanotubes in terms of their sorption potential for micropollutants removal. A comparative study was also conducted for activated carbons, fullerene C60 and aluminosilicate. The obtained results were used to plot the Langmuir and the Freundlich isotherms and to determine the kinetics of the adsorption of bisphenol A on the most effective sorbents.

\section{MATERIALS AND METHODS}

The study compared the structure and sorption potential of three types of carbon nanotubes (CNT), fullerene C60, two types of powdered activated carbon and aluminosilicate. Table 1 summarizes the primary characteristics of these materials.

The experiment was carried out using an artificial effluent, containing analytical standards of bisphenol A (BPA) and nonylphenol (NP). The composition of the artificial wastewater was described elsewhere [13].

Adsorption-desorption measurements at low temperature. In order to determine the structural parameters of the tested sorbents the sorption-desorption of nitrogen at $77.4 \mathrm{~K}$ 
was measured using a volumetric adsorption analyzer ASAP 2010 (Micrometrics, USA). The classification of the obtained isotherms was based on the five major types of isotherms suggested by the International Union of Pure and Applied Chemistry [2]. The software of the analyzer was used to calculate the specific surface area and pore size distribution using the BET equation and the density functional theory.

Table 1

Characteristics of the sorbents used in the study

\begin{tabular}{|c|c|c|c|c|c|}
\hline Type & Symbol & Manufacturer & $\begin{array}{l}\text { Purity } \\
{[\%]}\end{array}$ & $\begin{array}{l}\text { Structural } \\
\text { parameters }\end{array}$ & $\begin{array}{c}\text { Other } \\
\text { properties }\end{array}$ \\
\hline $\begin{array}{l}\text { Single-walled } \\
\text { carbon nanotubes }\end{array}$ & SWCNT & \multirow{3}{*}{$\begin{array}{l}\text { Chengdu } \\
\text { Organic } \\
\text { Chemistry }\end{array}$} & 95 & $\begin{array}{l}d=1-2 \mathrm{~nm} \\
l=5-30 \mu \mathrm{m}\end{array}$ & - \\
\hline $\begin{array}{l}\text { Multi-walled } \\
\text { carbon nanotubes }\end{array}$ & MWCNT & & 90 & $\begin{array}{l}d=1-2 \mathrm{~nm} \\
l=10-30 \mu \mathrm{m}\end{array}$ & - \\
\hline $\begin{array}{l}\text { Multi-walled } \\
\text { carbon nanotubes } \\
\text { with } \mathrm{COOH}\end{array}$ & $\begin{array}{l}\text { MWCNT } \\
-\mathrm{COOH}\end{array}$ & & 95 & $\begin{array}{l}d<8 \mathrm{~nm} \\
l=10-30 \mu \mathrm{m}\end{array}$ & $\begin{array}{l}-\mathrm{COOH} \\
\text { content } 3.86 \%\end{array}$ \\
\hline Fullerene & C60 & $\begin{array}{l}\text { Sigma } \\
\text { Aldrich }\end{array}$ & 99 & m.w. $=720.64 \mathrm{~g} / \mathrm{mol}$ & - \\
\hline \multirow{2}{*}{$\begin{array}{l}\text { Activated } \\
\text { carbon }\end{array}$} & AKPA-22 & Gryfskand & 95 & $\begin{array}{l}\text { grain size } \\
>0.12 \mathrm{~mm} \\
\end{array}$ & $\begin{array}{l}\text { Iiodine number } \\
900 \mathrm{mg} / \mathrm{g}\end{array}$ \\
\hline & Norit-SX2 & Brenntag & 95 & - & $\begin{array}{l}\text { Iiodine number } \\
800 \mathrm{mg} / \mathrm{g}\end{array}$ \\
\hline Aluminosilicate & M-Si & $\begin{array}{l}\text { Sigma } \\
\text { Aldrich }\end{array}$ & 95 & - & - \\
\hline
\end{tabular}

$d$ - diameter. $l$ - length.

Microscopic studies of carbon nanotubes. The microscopic image of the carbon nanotubes was obtained using a scanning electron microscope Supra 35, C. Zeiss without applying conductive layers on their surface. High resolution and accurate pictures of the analyzed samples were obtained using a high-performance detector Inlens Se operating at low beam voltage and in close proximity of the sample to the electron gun. Topography and texture of the carbon nanotubes were observed with an electron microscope S/TEM TITAN 80-300 from FEI, which was equipped with an energydispersive spectrometer EDS at an accelerating voltage of $80 \mathrm{kV}$. Sample preparation for the S/TEM imaging included in a first step dispersing the sample in spectrally pure ethanol using ultrasounds for $5 \mathrm{~min}$. Then, sample observation was carried out after a drop of the resulting suspension was applied over a copper mesh coated with a carbon film, and after the solvent was completely evaporated. 
Adsorption of micropollutants. The adsorption of micropollutants from the artificial effluent was carried out separately for BPA and NP (uncompetitive sorption) in static conditions using a laboratory shaker Aga Labor (150 rpm). Additionally, sorption under competitive conditions was conducted in experiment with mixture of BPA and NP. For this purpose, an adequate amount of the sorbent (in mg: 1.5, 3.0, 5.5, 7.5, 10.0) was added into Erlenmayer flasks, and next $100 \mathrm{~cm}^{3}$ of artificial effluent (concentration of BPA and NP were $1500 \mu \mathrm{g} / \mathrm{dm}^{3}$ ) was added. The flasks were shaken until the state of equilibrium was reached (it was determined in the preliminary study). A blank sample (without a sorbent) was prepared to determine the losses of the compounds in the control sample. After this time, the sorbent was separated from the solution using PTFE syringe filter with a pore size of $0.45 \mu \mathrm{m}$, and the resulting filtrates were analyzed for micropollutant concentrations. The analytical procedure included solid phase extraction and chromatographic determination with HPLC was described in our previously published paper [16]. All experiments were triplicated. The study allowed one to determine the relationship between the adsorption conditions (i.e. dose and type of sorbent, competitive and uncompetitive sorption) and the removal efficiency of micropollutants, which was determined from the equation:

$$
E=\frac{C_{0}-C_{k}}{C_{0}} \times 100 \%
$$

where: $E$ is the removal efficiency of micropollutants in the adsorption process, $C_{0}, C_{k}$ - concentrations of the organic micropollutants, initial $(0)$ and after adsorption $(k)$.

Determination of adsorption isotherms. The adsorption capacity of the activated carbons and the carbon nanotubes were determined based on the adsorption isotherms of BPA. The following doses of the sorbent were used (in mg) 1.0, 1.2, 1.7, 1.9, 2.0, 2.4, 2.5, 3.4, 3.6, 4.1, 4.3, 4.4, 4.6, 4.8, 4.9, 5.2, 5.5, 5.6, 5.9, 6.4, 6.5, 6.6, 6.7 . 7.6, 8.2, $8.4,8.9,9.1,9.6,9.8,10.2,10.9,12.0$ in the experiment, and the concentration of BPA in the artificial effluent was in the range of $800-2000 \mu \mathrm{g} / \mathrm{dm}^{3}$. The process was conducted at $23 \pm 1{ }^{\circ} \mathrm{C}$ until a dynamic equilibrium for a given adsorbate-adsorbent system was established. The amount of BPA adsorbed on the nanotubes was determined from the following equation [17]:

$$
Q_{e}=\frac{v\left(C_{0}-C_{e}\right)}{m}
$$

where: $Q_{e}$ - adsorbed amount of the adsorbate $(\mathrm{mg} / \mathrm{g}), C_{0}$ and $C_{e}-$ initial and equilibrium concentrations of the adsorbate $\left(\mathrm{mg} / \mathrm{dm}^{3}\right), m$ - weight of the sorbent $(\mathrm{g}), v$ - volume in which the adsorption was performed $\left(\mathrm{dm}^{3}\right)$. 
In order to describe the experimental data, we used the Langmuir model

$$
Q_{e}=\frac{a b C_{e}}{1+b C_{e}}
$$

and the Freundlich model [17]

$$
Q_{e}=K_{f} C_{e}^{1 / n}
$$

where: $a$ is the maximum sorption capacity ( $\mathrm{mg} / \mathrm{g}), b$ - the Langmuir constant $\left(\mathrm{dm}^{3} / \mathrm{mg}\right)$, $K_{f}$ - the Freundlich constant $\left((\mathrm{mg} / \mathrm{g})\left(\mathrm{dm}^{3} / \mathrm{mg}\right)^{n}\right), n$ - the surface heterogeneity parameter.

The model was fitted to the experimental data using the Microsoft Excel spreadsheet with the Solver add-in. The least-squares method was used to determine the constants of the Freundlich and Langmuir equations.

Determination of the adsorption kinetics. The adsorption kinetics study was carried out for the activated carbons and the carbon nanotubes. Aqueous solution of BPA at a concentration of $1000 \mu \mathrm{g} / \mathrm{dm}^{3}$ and sorbents doses of $80 \mathrm{mg} / \mathrm{dm}^{3}$ were applied. The sorption process was conducted for $0.5,1,3,5,10,15,30,45,60 \mathrm{~min}$ and then at hourly intervals until an equilibrium was established. The adsorbed amount of BPA was calculated from the equation [17]:

$$
Q_{t}=\frac{v\left(C_{0}-C_{t}\right)}{m}
$$

where: $Q_{t}$ is the amount of adsorbate adsorbed at time $t(\mathrm{mg} / \mathrm{g}), C_{t}-$ concentration of the adsorbate at a given time $t\left(\mathrm{mg} / \mathrm{dm}^{3}\right)$.

In order to describe the experimental data, the pseudo-second order kinetic equation was used [18]:

$$
\frac{t}{Q_{t}}=\frac{1}{K_{2} Q_{e}^{2}}+\frac{1}{Q_{e}}
$$

where: $K_{2}$ is the pseudo-second order adsorption rate constant $(\mathrm{g} /(\mathrm{mg} \cdot \mathrm{min}))$.

The pseudo-second order kinetic equation was used to determine the adsorption half-time $t_{1 / 2}(\mathrm{~min})$

$$
t_{1 / 2}=\frac{1}{K_{2} Q_{e}}
$$


and initial reaction rate $h(\mathrm{mg} /(\mathrm{g} \cdot \mathrm{min}))[13]$ :

$$
h=K_{2} Q_{e}^{2}
$$

\section{RESULTS AND DISCUSSION}

\subsection{STRUCTURE AND PROPERTIES OF SORBENTS}

The analyzed carbon nanotubes (CNT) imaged using scanning electron microscopy are shown in Fig. 1. The nanotubes undergo various aggregation pathways by mutual intertwining and twisting.
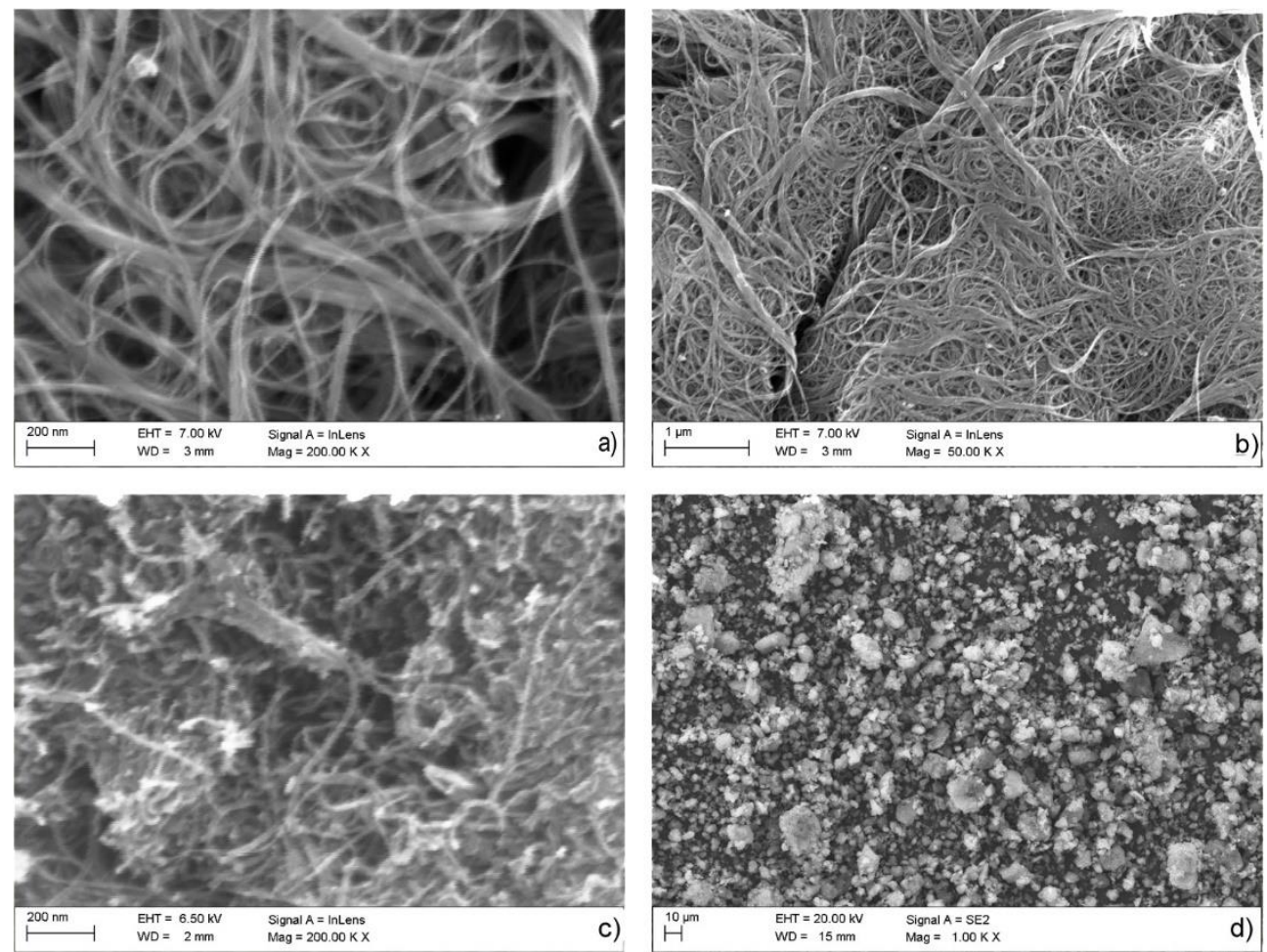

Fig. 1. SEM images of the carbon nanotubes: SWCNT (a, b), MWCNT (c, d)

Aggregation of multi-walled nanotubes was so strong that they formed dense granules, and single multi-walled structures were not visible (Figs. 1c, d). In the single-walled nanotubes, such strong entanglement was not observed; they formed bundles typical of these materials (Figs. 1a, b). As the result of aggregation, some of the sorption 
surfaces are blocked and thus their sorption capacity becomes reduced. In contrast, under ideal conditions, where no aggregation of CNT occurs, the adsorbing region is the outermost surface, the space between successive layers, and the interior of a cylindrical nanotube $[10,11]$.

The use of transmission electron microscopy allowed obtaining full-range imaging of the single-walled carbon nanotubes (SWCNT) and multi-walled carbon nanotubes (MWCNT) covering both their clusters (Fig. 2) as well as clearly visible graphene sheets forming their structure (Fig. 3). The comparison of the images of both samples shows that SWCNT were characterized by higher purity, which was manifested by the lack of visible metallic impurities originating from catalysts used in the production of CNTs as well as the deposits of amorphous carbon (Fig. 2). In terms of the sorption properties of nanotubes it is an important parameter because the contaminants occupy potential sorption sites.
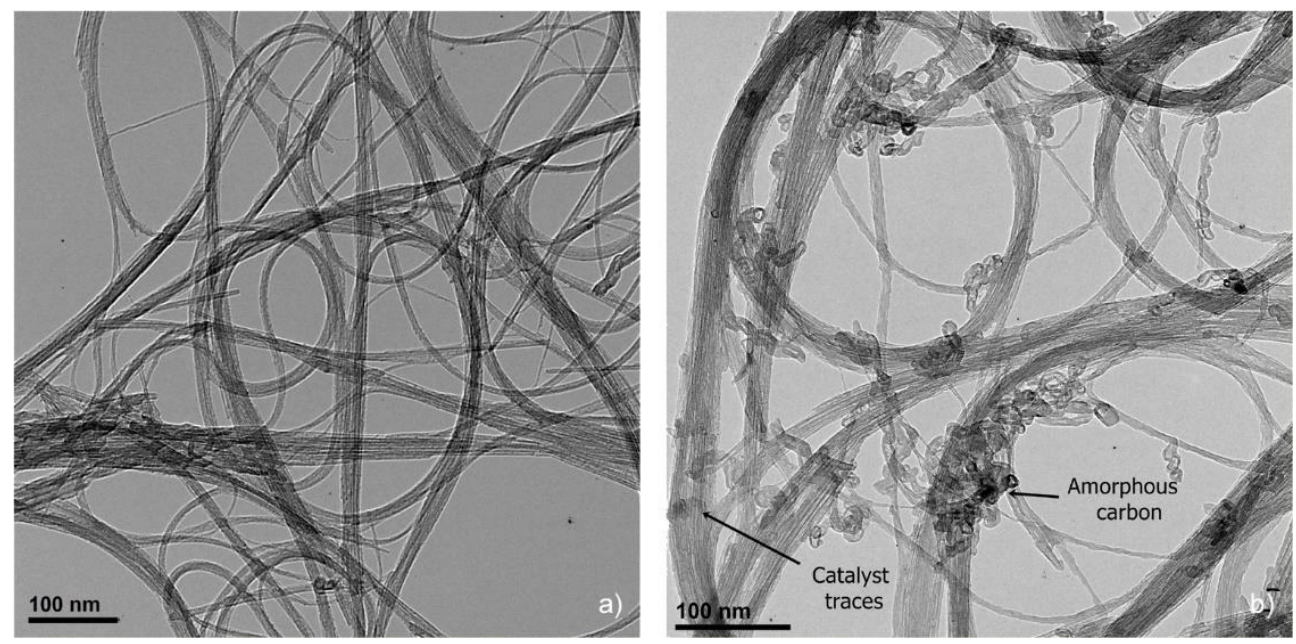

Fig. 2. TEM images of the carbon nanotubes: SWCNT (a), MWCNT (b)

The difference in the structure of the SWCNT and MWCNT is well visible in Fig. 3. The SWCNT have a diameter of about 1-2 nm (Fig. 3b) and the MWCNT of about $10 \mathrm{~nm}$ (Fig. 3c). However, their length in both cases exceeded $100 \mathrm{~nm}$, as in the obtained TEM images, it is possible to see only fragments, and not the entire cylinders (according to the manufacturer, the length of the CNT is 5-30 $\mu \mathrm{m}$ ). It can be concluded that the tested nanotubes were characterized by a very high length-to-diameter ratio, which indicates very large outer surface area. The high-resolution TEM imagining (HRTEM) shows also that the MWCNT were closed with various hemispherical end-caps. This structural feature most probably negatively affected the sorption properties, because the adsorbate molecules had limited access to the internal surface of the adsorbent. 

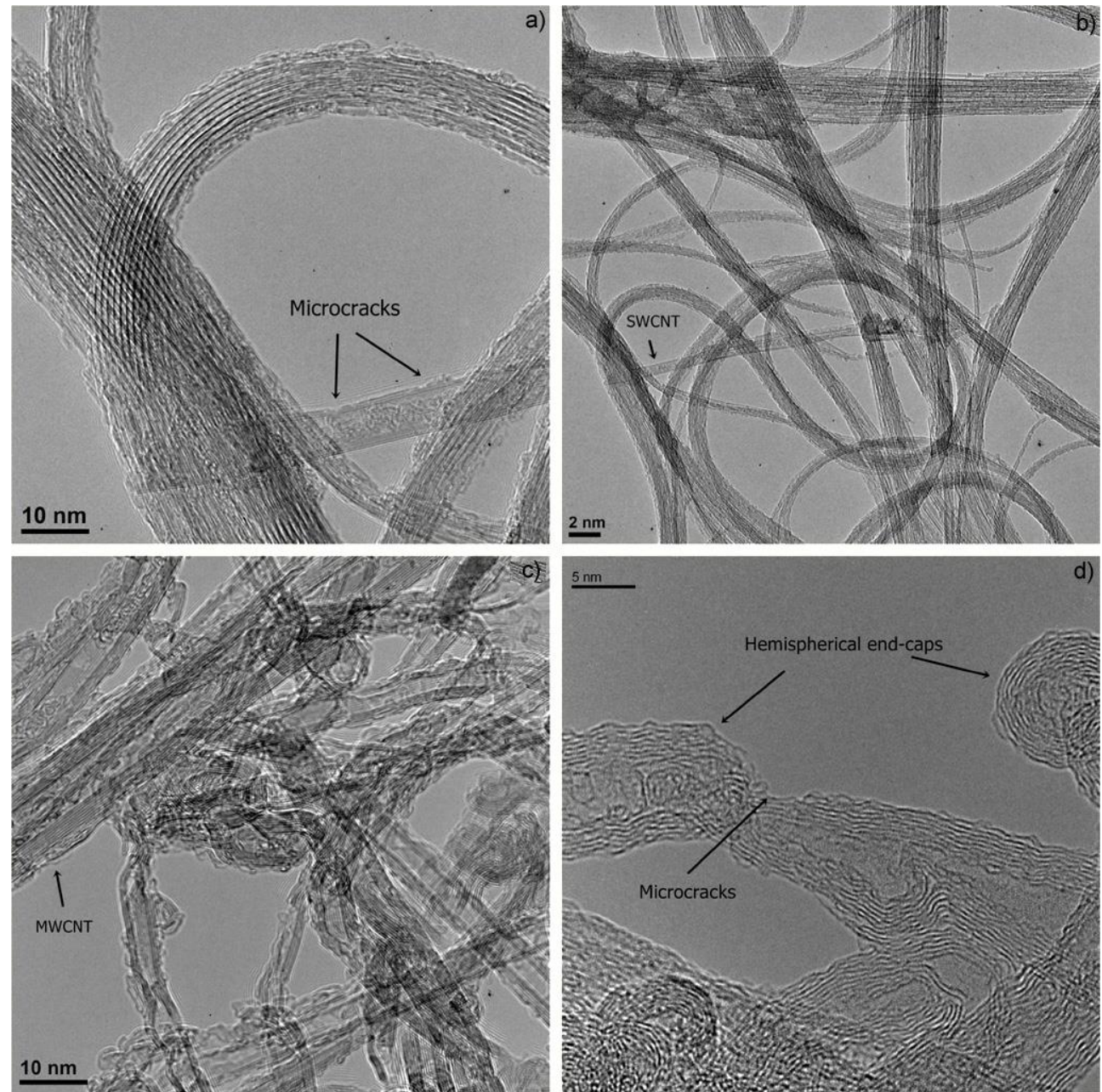

Fig. 3. High-resolution TEM images of the carbon nanotubes: SWCNT (a, b), MWCNT (c, d)

It is also important that the structure and the exterior walls of the SWCNT and MWCNT contained microcracks, which disrupted their integrity (Figs. 3a, d). Most commonly, this kind of deformations is the result of different methods used for cleaning or activation of nanotubes. These methods include, e.g. treatment with concentrated mineral acids, which penetrate the walls of the nanotubes and form variously-sized pores in their structure.

Figure 4 shows the pore size distribution of the carbon nanotubes. The obtained results suggest also that the porous structure of SWCNT consisted mostly of microporous fraction $(\leq 2 \mathrm{~nm})$. In contrast, the structure of the MWCNT and MWCNT-COOH nanotubes apart from a considerable proportion of micropores contained also numerous 
mesopores $(5-50 \mathrm{~nm})$. These results corroborate the microscopic observations, which showed that the structure of the MWCNT contained more deformations and microcracks forming pores in their walls.

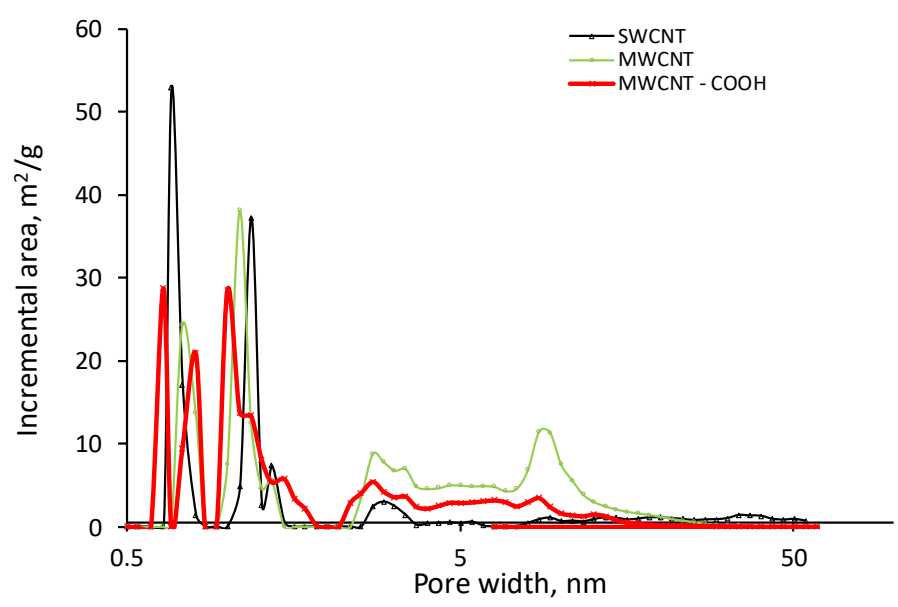

Fig. 4. Pore size distributions of the carbon nanotubes

Figure 5 illustrates pore size distribution for the activated carbons (AKPA and SX2) and aluminosilicate. The porous structure of the two carbons was dominated by micropores with effective diameters in the range of $0.7-2 \mathrm{~nm}$ while aluminosilicate was dominated by the mesopores with diameters in the range of ca. $2.3-5 \mathrm{~nm}$.

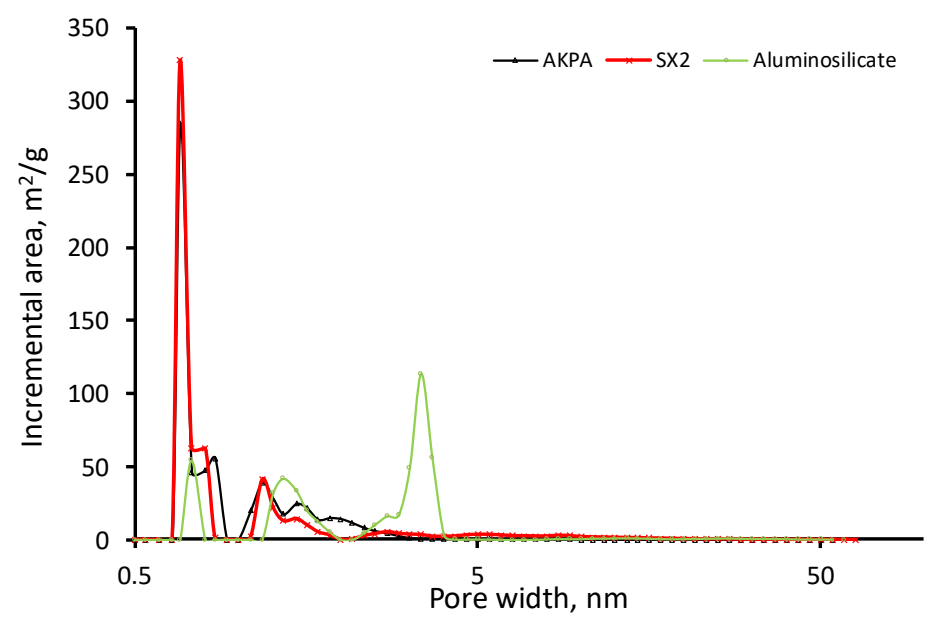

Fig. 5. Pore size distribution of the activated carbons and aluminosilicate 
The results obtained for fullerene C60 showed very small proportion of micro- and mesopores, which indicated the actual lack of a porous structure (Fig. 6).

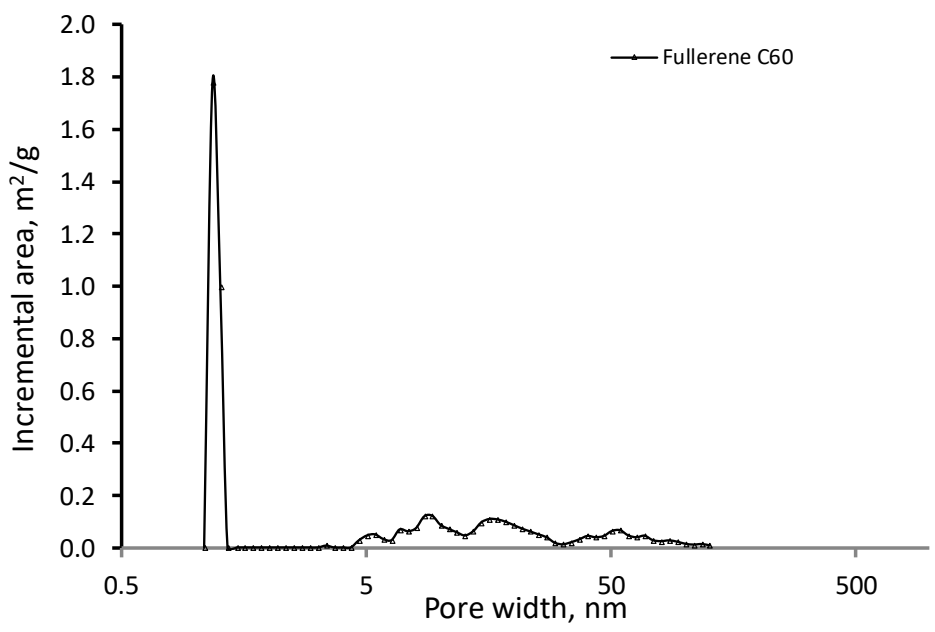

Fig. 6. Pore size distribution of fullerene C60

Table 2

Sorption characteristics of the sorbents used in the study

\begin{tabular}{|l|c|c|}
\hline \multicolumn{1}{|c|}{ Parameter } & $\begin{array}{c}\text { Specific surface area } \\
{\left[\mathrm{m}^{2} / \mathrm{g}\right]}\end{array}$ & $\begin{array}{c}\text { Pore volume } \\
{\left[\mathrm{cm}^{3} / \mathrm{g}\right]}\end{array}$ \\
\hline SWCNT & 467.38 & 0.39 \\
\hline MWCNT & 455.45 & 0.60 \\
\hline MWCNT-COOH & 338.18 & 0.28 \\
\hline Fullerene C60 & 14.77 & 0.03 \\
\hline AKPA & 900.40 & 0.36 \\
\hline SX2 & 821.76 & 0.49 \\
\hline Aluminosilica & 886.50 & 0.76 \\
\hline
\end{tabular}

Table 2 lists the parameters of the porous structure of the absorbents, this is specific surface area and pore volume, which were determined based on the nitrogen sorptiondesorption measurements. It shows that the activated carbons and aluminosilicate had the largest specific surface area, and the fullerene C60 had the smallest one. The specific surface area of the carbon nanotubes was ca. half that of the activated carbons and was in the following order: SWCNT > MWCNT > MWCNT-COOH. A significant reduction in the specific surface area of the MWCNT- $\mathrm{COOH}$ as compared to the unmodified MWCNT was most probably due to the phenomenon in which some of the sorption sites are occupied by immobilized carboxyl groups. 


\subsection{REMOVAL EFFICIENCY OF MICROPOLLUTANTS \\ IN THE ADSORPTION ON STUDIED ADSORBENTS}

Figure 7 shows a comparison of the efficiency of the removal of BPA and NP in the adsorption on the studied sorbents. For all the sorbents higher removal efficiency was obtained for NP than for BPA. This was due to NP higher affinity for adsorption resulting from the higher values of the $\log K_{\text {ow }}$ (5.92) [19] in comparison to BPA $\log K_{\text {ow }}$ (3.32) [20].
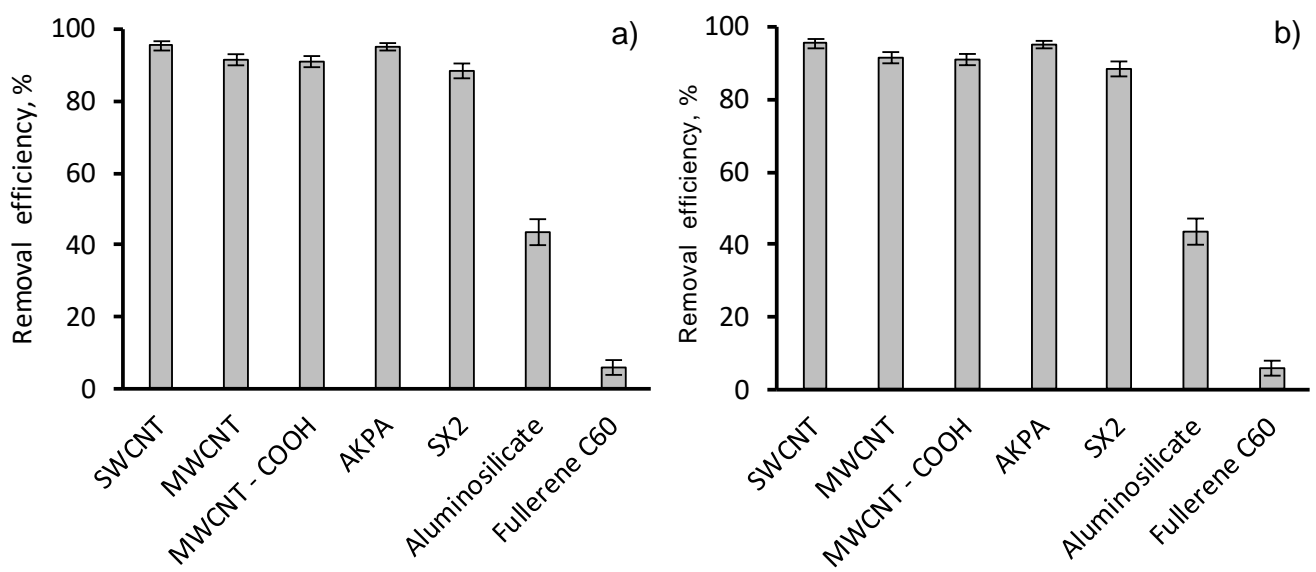

Fig. 7. Efficiency of the studied sorbents in adsorbing BPA and NP from aqueous solution (initial concentration of BPA (a) and NP (b) $-1500 \mu \mathrm{g} / \mathrm{dm}^{3}$, sorbent concentration $-100 \mathrm{mg} / \mathrm{dm}^{3}$ )

In contrast, the evaluation of the adsorption efficiency depending on the sorbent used in the process showed that the SWCNT had the highest sorption capacity for both BPA and NP. They allowed for almost complete removal of the compounds from the artificial wastewater, which was $95.4 \%$ (BPA) and 98.2\% (NP). Comparable treatment results were obtained using the AKPA carbon, i.e. $94.9 \%$ and $97.4 \%$ for BPA and NP. Slightly lower sorption capacity for the studied micropollutants was found for the MWCNT and the activated carbon SX2. However, the application of aluminosilicate allowed one to remove BPA and NP at a moderate level of $43.55 \%$ for BPA and $50.0 \%$ for NP. Fullerene had a very low sorption capacity, which was also already indicated by the very low specific surface area of this material.

It can be observed that the materials containing mesopores had lower sorption capacities for BPA and NP than materials with microporous structure. This was best corroborated by the results for aluminosilicate, which despite having a high specific surface area did not display high removal efficiency of the micropollutants. On the other hand, the sorbents with typical microporous structure, this is SWCNT and AKPA, had the best adsorption properties. Due to the fact that the efficiency of this process in the case of 
aluminosilicate and fullerene 60 for both BPA and NP was lower than 50\%, these adsorbents were excluded from further investigations.

The study also showed that the removal efficiency of BPA and NP increases with increasing concentrations (in the range of $15-100 \mathrm{mg} / \mathrm{dm}^{3}$ ) of the MWCNT (Fig. 8). A higher concentration of sorbent translated to a larger area available for the adsorption of the molecules of both adsorbates. At the low concentration range of the MWCNT $\left(15-30 \mathrm{mg} / \mathrm{dm}^{3}\right)$ we observed marked increase in the removal efficiency of BPA and NP. However, the removal efficiency of micropollutants increased only by several percent when the concentration of MWCNT was higher than $55 \mathrm{mg} / \mathrm{dm}^{3}$.

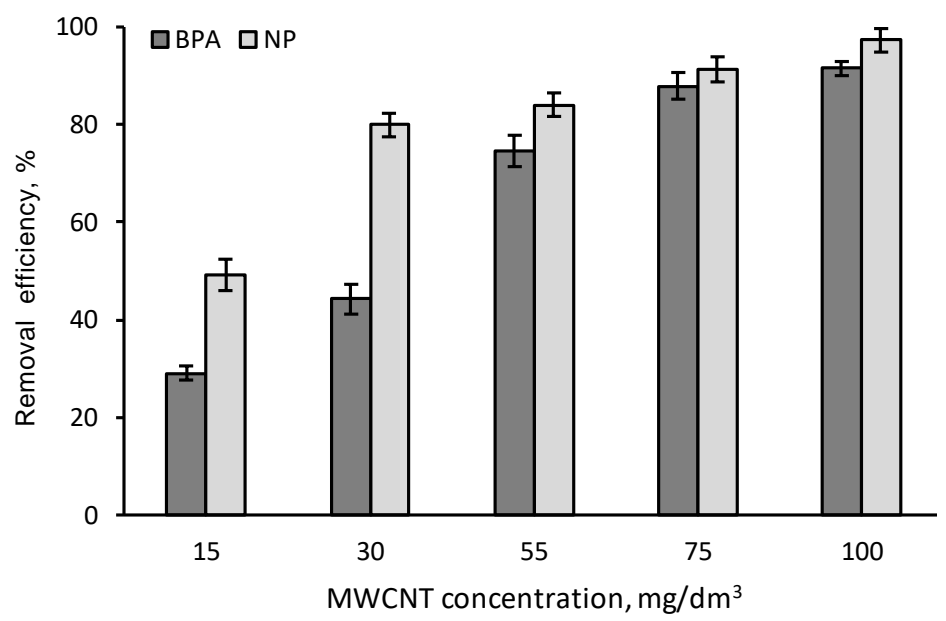

Fig. 8. Effect of MWCNT dose on BPA and NP removal (initial concentration of BPA and NP $-1500 \mu \mathrm{g} / \mathrm{dm}^{3}$ )

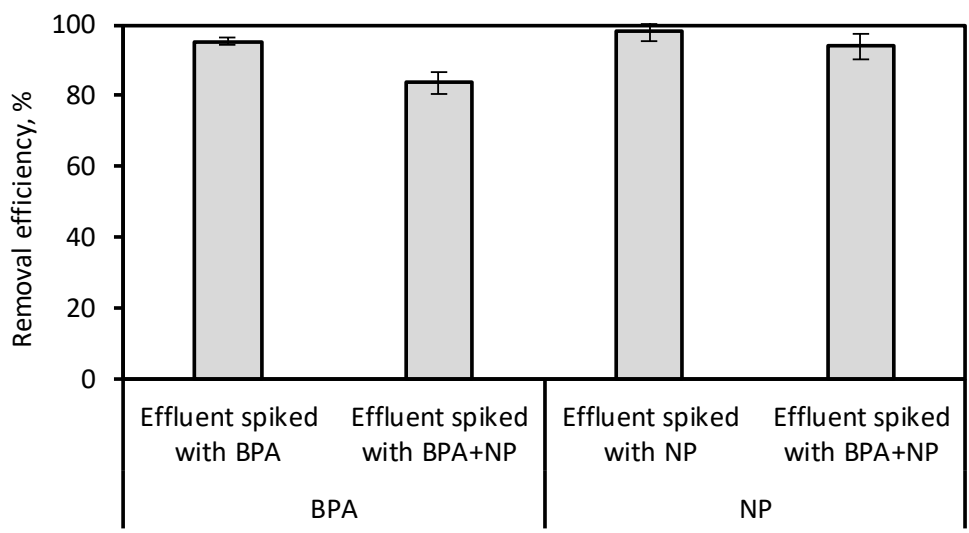

Fig. 9. Comparison of the micropollutant adsorption in single- and two-component systems (initial concentration of BPA and NP $-1500 \mu \mathrm{g} / \mathrm{dm}^{3}$, SWCNT concentration $-100 \mathrm{mg} / \mathrm{dm}^{3}$ ) 
The efficiency of adsorption of the micropollutants was lower when they were removed from the mixture BPA + NP in comparison to adsorption efficiency of a single micropollutant (Fig. 9). The mixture of BPA and NP was found to affect BPA adsorption to a higher extent. In other words, it can be assumed that the presence of NP limited the adsorption of BPA more than BPA limited the adsorption of NP. The reduced adsorption of BPA in this multi-component mixture was mainly due to greater affinity of NP for the adsorption. Therefore, it occupied the available sorption sites preferentially.

\subsection{KINETICS OF ADSORPTION OF BISPHENOL A}

The time dependences of $Q_{t}$ were plotted based on the calculated amount of BPA adsorbed at a given time. The results for the carbon nanotubes and the activated carbons are shown in Fig. 10.

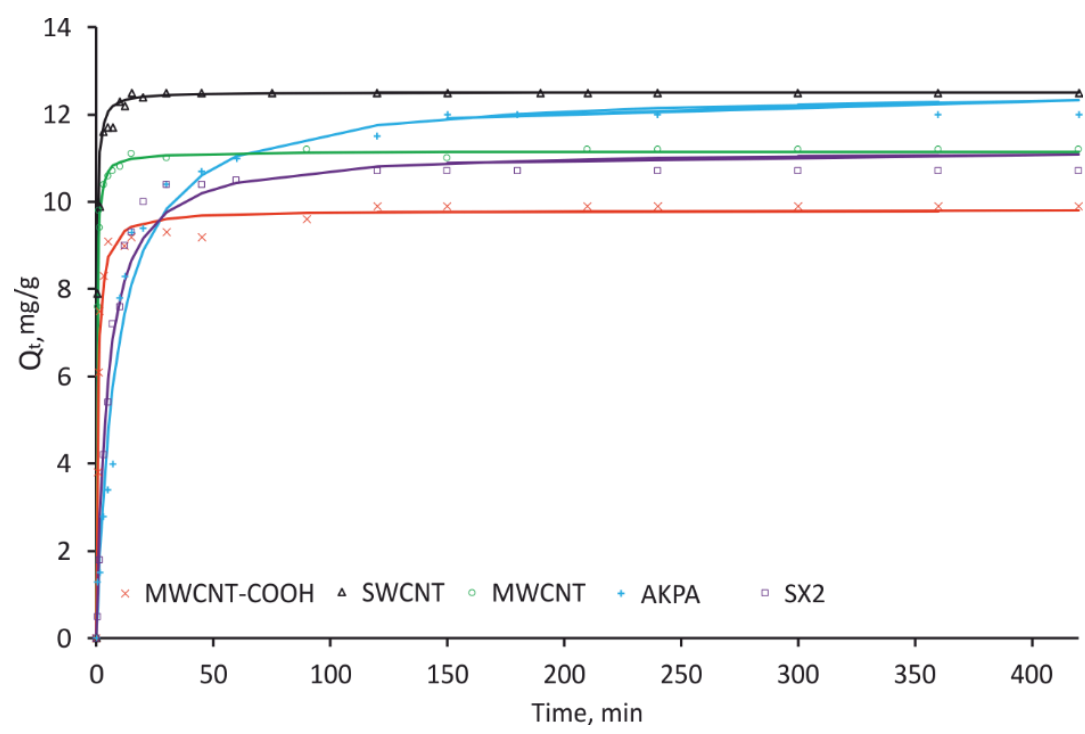

Fig. 10. Temporal behavior of the amount of the adsorbed BPA

on the carbon nanotubes and the activated carbons. Initial concentration of BPA $-1000 \mu \mathrm{g} / \mathrm{dm}^{3}$, sorbent concentration $-80 \mathrm{mg} / \mathrm{dm}^{3}$. CNTs adsorption data adopted from [13]

The kinetic equilibrium for the carbon nanotubes was established very quickly, this is, after about 10, 15 and $30 \mathrm{~min}$ for SWCNT, MWCNT, MWCNT-COOH, respectively. After this time, the amount of adsorbed BPA was $12.5,11.2$, and $9.9 \mathrm{mg} / \mathrm{g}$ for SWCNT, MWCNT, MWCNT-COOH, respectively. Adsorption on activated carbons was much slower, and the equilibrium was established after ca. 120-180 min, and the amount of adsorbed BPA was comparable with the result for SWCNT.

Time dependence of $t / Q_{t}$ determined from the pseudo-second order kinetic equation was used to calculate the adsorption rate constant $K_{2}$, half-adsorption time $t_{1 / 2}$, and the 


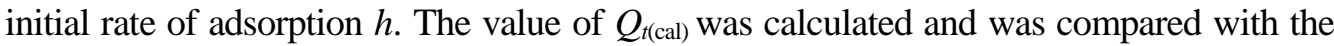
experimental data $\left(Q_{t(\mathrm{exp})}\right)$ using the least-squares method. The obtained high correlation coefficients indicate that the BPA adsorption kinetics proceeded according to the assumptions of the pseudo-second order equation. The values of the parameters determined for the carbon nanotubes and the activated carbons are presented in Table 3. They confirm that the sorption process was much quicker for the carbon nanotubes than for the activated carbon.

Table 3

Parameters of the pseudo-second order kinetic equation for the adsorption of BPA on the carbon nanotubes and activated carbons

\begin{tabular}{|l|c|c|c|c|c|c|}
\hline \multicolumn{1}{|c|}{ Sorbent } & $\begin{array}{c}K_{2} \\
{[\mathrm{~g} /(\mathrm{mg} \cdot \mathrm{min})]}\end{array}$ & $\begin{array}{c}Q_{t(\mathrm{exp})} \\
{[\mathrm{mg} / \mathrm{g}]}\end{array}$ & $\begin{array}{c}Q_{t(\mathrm{cal})} \\
{[\mathrm{mg} / \mathrm{g}]}\end{array}$ & $\begin{array}{c}t_{1 / 2} \\
{[\mathrm{~min}]}\end{array}$ & $\begin{array}{c}h \\
{[\mathrm{mg} /(\mathrm{g} \cdot \mathrm{min})]}\end{array}$ & $R^{2}$ \\
\hline SWCNT & 0.430 & 12.50 & 12.51 & 0.18 & 67.35 & 0.9822 \\
\hline MWCNT & 0.418 & 11.20 & 11.15 & 0.21 & 51.97 & 0.9946 \\
\hline MWCNT-COOH & 0.165 & 9.90 & 9.80 & 0.61 & 15.89 & 0.9880 \\
\hline AKPA & 0.009 & 12.00 & 12.47 & 8.56 & 1.45 & 0.9731 \\
\hline SX2 & 0.201 & 10.7 & 11.2 & 4.42 & 2.53 & 0.9946 \\
\hline
\end{tabular}

The values of the adsorption rate and the half-adsorption time for the MWCNT and SWCNT are similar, while the adsorption on the modified MWCNT was slightly slower. The increased rate of adsorption on the CNT compared to the activated carbons is related to the type of adsorbing surface. Adsorbing surface of activated carbons is mainly within the microporous structure to which the adsorbate molecules are transported through macro- and mesopores, whereas the adsorbing surface of the carbon nanotubes is primarily the outer one, being in direct contact with the adsorbate molecules. Thus it can be concluded that the slower adsorption on the modified MWCNT was associated with their more porous structure compared to the unmodified CNTs. It cannot be excluded that the CNT were responsible for physical adsorption and the AKPA carbon for chemisorption. The physical adsorption is quicker compared to the chemical adsorption,because it does not require activation energy in the adsorbent-adsorbate system. The obtained results are important for the practical applications of static adsorption. Very fast adsorption on carbon nanotubes allows one to use all their operational capacity in a very short period of time, which implies, among others, low volumes of the wastewater treatment vessels.

\subsection{LANGMUIR AND FREUNDLICH ISOTHERMS}

FOR THE DESCRIPTION OF THE SORPTION OF BISPHENOL A

The isotherms describing the adsorption of BPA on the carbon nanotubes and the activated carbons derived from the Langmuir and Freundlich models and are shown in Figs. 11a, b. 

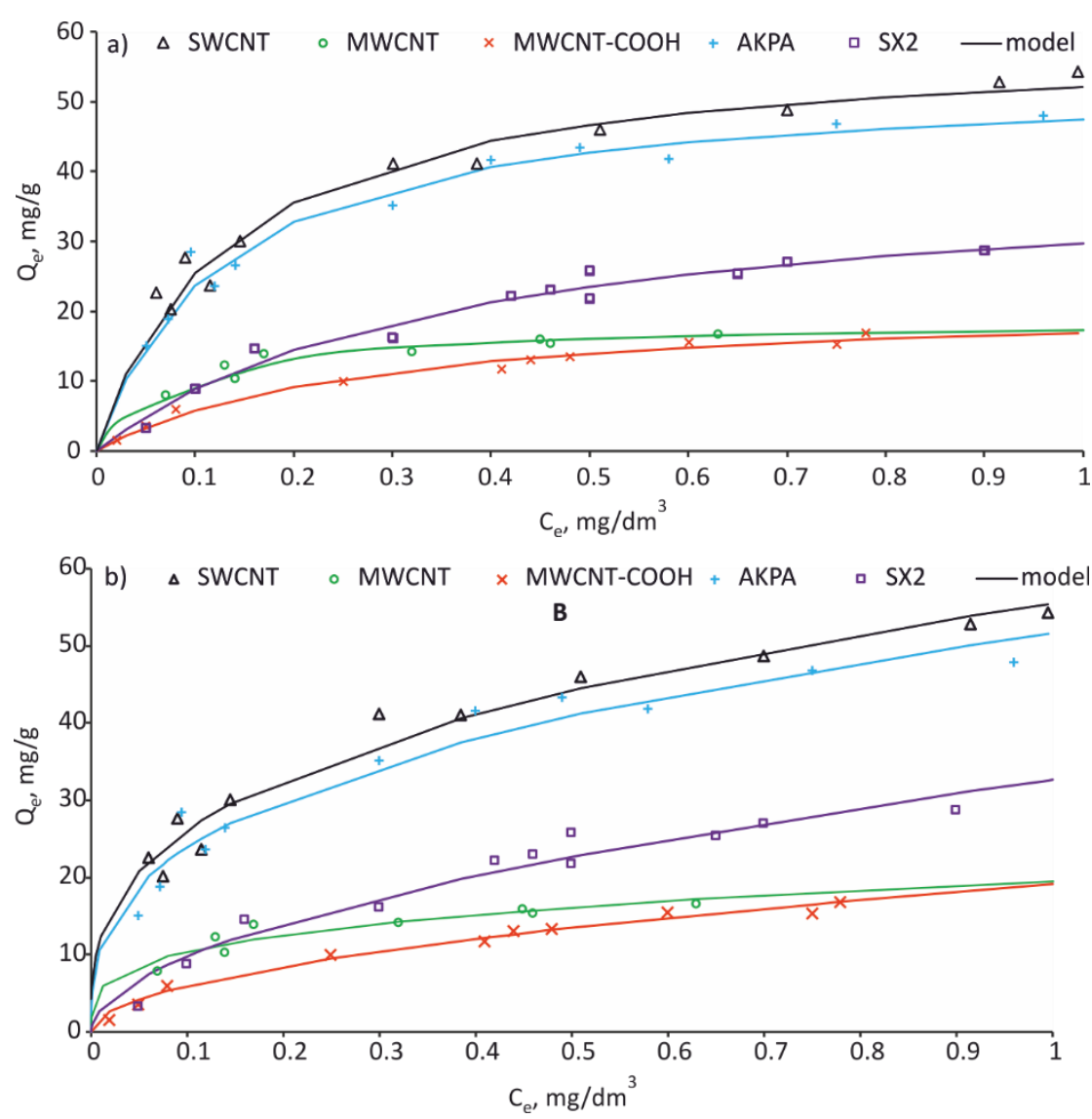

Fig. 11. Langmuir (a) and Freundlich (b) adsorption isotherms of BPA on carbon nanotubes and activated carbons. Initial concentration of BPA $800-2000 \mu \mathrm{g} / \mathrm{dm}^{3}$,

sorbent concentration $-10-120 \mathrm{mg} / \mathrm{dm}^{3}$. CNTs adsorption data adopted from [13]

The parameters characterizing the process of adsorption were calculated from the Freundlich and Langmuir models (Table 4). Based on these data, it can be concluded that both models satisfactorily described the course of adsorption. From the shape of the isotherms it is evident that the single-walled nanotubes exhibited the greatest sorption capacity. This is also confirmed by the value of the $K_{f}$ constant, and the maximum adsorption $a$, which were both the highest for SWCNT. Similar values of these coefficients were obtained for the AKPA carbon. Due to the efficiency of the adsorption the obtained isotherms can be ranked as follows: $\mathrm{SWCNT}>\mathrm{AKPA}>\mathrm{SX} 2>\mathrm{MWCNT}>\mathrm{MWCNT}$ $-\mathrm{COOH}$. The adsorption of BPA on MWCNT was more advantageous on unmodified nanotubes compared to the nanotubes with a modified surface due to larger specific surface area of the former ones, as well as from the presence of $\mathrm{COOH}$ groups on the surface of the latter. The experimental assessment of the sorption capacity of the carbon 
nanotubes correlates well with the results obtained from the low-temperature sorption-desorption isotherms of nitrogen, which shows that the three studied nanotubes had specific surface area in the increasing order of MWCNT-COOH < MWCNT < SWCNT. When the value of the $\mathrm{n}$ constant is less than 10 , it is indicated that the adsorption occurs on an energetically heterogeneous surface, which corresponds to multilayer adsorption.

Table 4

Parameters of the Freundlich and Langmuir equations and correlation coefficients for the adsorption of BPA on carbon nanotubes and the activated carbons

\begin{tabular}{|l|c|c|c|c|c|c|}
\hline \multirow{2}{*}{ Sorbent } & \multicolumn{3}{|c|}{ Freundlich model } & \multicolumn{3}{c|}{ Langmuir model } \\
\cline { 2 - 7 } & $K_{f}\left[(\mathrm{mg} / \mathrm{g})\left(\mathrm{dm}^{3} / \mathrm{mg}\right)^{n}\right]$ & $n$ & $R^{2}$ & $b\left[\mathrm{dm}^{3} / \mathrm{mg}\right]$ & $a[\mathrm{mg} / \mathrm{g}]$ & $R^{2}$ \\
\hline SWCNT & 55.47 & 3.06 & 0.968 & 7.62 & 58.96 & 0.961 \\
\hline MWCNT & 19.44 & 3.68 & 0.858 & 11.89 & 18.72 & 0.909 \\
\hline MWCNT-COOH & 19.12 & 1.98 & 0.982 & 3.74 & 21.42 & 0.983 \\
\hline AKPA & 51.64 & 2.99 & 0.940 & 8.15 & 53.38 & 0.961 \\
\hline SX2 & 32.63 & 1.92 & 0.943 & 2.79 & 40.35 & 0.968 \\
\hline
\end{tabular}

\section{SUMMARY}

The assessment of the sorption capacity of selected sorbents was based on the analysis of their porous structure, as well as on the experimental study addressing the adsorption of BPA and NP from the artificial wastewater. The results of the experiment on the sorption-desorption of nitrogen showed that specific surface area of the studied materials was in the decreasing order of activated carbons and aluminosilicate (both with the largest area), and then the carbon nanotubes and fullerene C60. It was shown that this parameter did not fully reflect their potential sorption. This is because aluminosilicate, despite its high specific surface area, allowed only 50\% removal of the studied compounds. On the other hand, the surface area of single-walled nanotubes was ca. half that of the activated carbons, but the adsorption of BPA and NP was the highest for the nanotubes. The comparison of the sorption properties of the carbon nanotubes showed marked discrepancies, since the MWCNT generally had lower sorption capacity than the SWCNT. This was due to both the presence of the catalysts molecules or amorphous carbon and a high degree of entanglement of the MWCNT as compared to the SWCNT.

The experimental isotherms for the adsorption of BPA fitted well with the theoretical models of Langmuir and Freundlich for all the sorbents (except for the MWCNT).

While viewing the process from the implementation perspective it should be noted that the rate of adsorption on carbon nanotubes allows using all their sorption capacity in a very short time. In a full-scale system it translates to a significant reduction in the cost of treating the water or waste water, which is due to much smaller reactors and 
shorter contact times. The obtained results clearly show the advantage of carbon nanotubes over activated carbons.

\section{ACKNOWLEDGEMENTS}

This work was performed with financial support from the National Science Centre. Poland under grant No. DEC-2011/01/n/st8/02413. It was carried out with equipment purchased for the Project SilesianBIOFARM. Centre for Biotechnology. Bioengineering and Bioinformatics. co-financed by the ERDF (OP IE. 2007-2013t). Author Gabriela Kamińska received funding from National Science Centre (Poland) for preparing $\mathrm{PhD}$ thesis under grant number DEC-2014/12/T/ST8/00668.

\section{REFERENCES}

[1] HeEkyong O., TARO U., DAI S., HyUNOOK K., Effect of natural organic matter on adsorption of ionic and non-ionic pharmaceuticals to granular activated carbon, Environ. Prot. Eng., 2013, 39 (4), 15.

[2] Bansal R. C., Goyal M., Activated carbon adsorption, CRC Taylor ad Francis, Boca Raton 2005.

[3] PATIÑo Y., DíAz E., ORdóÑEZ S., Performance of different carbonaceous materials for emerging pollutants adsorption, Chemosphere, 2015, 119, 124.

[4] ÇEÇEN F., AKTAS Ö., Activated carbon for water and wastewater treatment, Wiley-VCH Verlag GmbH \& Co. KGaA, Weinheim 2011.

[5] Kennedy A.M., Reinert A.M., KnAPPe D.R., Ferrer I., Summers R.S., Full-and pilot-scale GAC adsorption of organic micropollutants, Water Res., 2015, 68, 238.

[6] Golestanifar H., Haibati B., Amini H., Dehghani M. H., Asadi A., Removal of hexavalent chromium from aqueous solution by adsorption on $\gamma$-alumina nanoparticles, Environ. Prot. Eng., 2015, 41 (2), 133.

[7] Upadhyayula V., Deng S., Mitchell M., Smith G., Application of carbon nanotube technology for removal of contaminants in drinking water. A review, Sci. Total Environ., 2009, 408, 1.

[8] Yu J.-G.,Zhao X.-H., Yang H., Chen X.-H., YAng Q., Yu L.-Y., JiAnG J.-H., Chen X.-Q., A queous adsorption and removal of organic contaminants by carbon nanotubes, Sci. Total Environ., 2014, 482-483, 241.

[9] Bohdziewicz J., Kamińska G., Pawlyta M., Lukowiec D., Comparison of effectiveness of advanced treatment of municipal wastewater by sorption and nanofiltration. Separate processes and integrated systems, Environ. Prot. Eng., 2015, 41 (2), 119.

[10] Gatica S., Bojan M., Stan G., Cole M., Quasi-one- and two-dimensional transitions of gases adsorbed on nanotube bundles, J. Chem. Phys., 2001, 114, 3765.

[11] Agninotri S., Mota J., Rostam-Abadi M., Rood M., Structural characterization of single-walled carbon nanotube bundles by experiment and molecular simulation, Langmuir, 2005, 21, 896.

[12] PAN B., Lin D., MAShayeKhi H., XING B., Adsorption and hysteresis of bisphenol A and 17 $\alpha$-ethinyl estradiol on carbon nanomaterials, Environ. Sci. Technol., 2008, 42, 5480.

[13] BohDZIEwICZ J., KAMiŃSKa G., Kinetics and equilibrium of the sorption of bisphenol A by carbon nanotubes from wastewater, Water Sci. Technol., 2013, 68 (6), 1306.

[14] Gogotsi Y., Carbon Nanomaterials, Taylor \& Francis, Boca Raton 2006.

[15] YANG K., XING B., Desorption of polycyclic aromatic hydrocarbons from carbon nanomaterial in waters, Environ. Pollut., 2007, 145, 529.

[16] Kamińska G. Bohdziewicz J., Palacio L., Hernández A., Prádanos P., Polyacrylonitrile membranes modified with carbon nanotubes: characterization and micropollutants removal analysis, Des. Water Treat., 2016, 53, 1344.

[17] Kowal A.L., Water Treatment, Wydawnictwo Naukowe PWN, Warsaw 2005 (in Polish). 
[18] TомсZAK E., Removal of pollutants from aqueous solutions using filled bed column. Modelling of adsorption dynamics, Zeszyty Naukowe, Politechnika Lódzka, 2011, 1102 (in Polish).

[19] DudZIAK M., BoDZEK M., Removal of estrogenic micropollutants from water solutions by high-pressure driven membrane processes. Ochr. Środ., 2009, 31 (3), 33 (in Polish).

[20] Dudziak M., BodzeK M., Separation of bisphenol A by nanofiltration under conditions of membrane surface saturation, Ochr. Środ., 2008, 30 (2), 17 (in Polish). 